\title{
Effect of noise stress on cardiovascular system in adult male albino rat: implication of stress hormones, endothelial dysfunction and oxidative stress
}

\author{
Mona A. Said and Ola A. El-Gohary \\ Physiology Department, Faculty of Medicine, Benha University, Benha, Qalubia, Egypt
}

\begin{abstract}
Noise pollution has been realized as an environmental stressor associated with modern life style that affects our health without being consciously aware of it. The present study investigated the effect of acute, chronic intermittent and chronic continuous exposure to noise of intensity $80-100 \mathrm{~dB}$ on heart rate and mean systemic arterial blood pressure in rats and the possible underlying mechanisms. Noise stress causes significant increase in heart rate, mean systemic arterial blood pressure as well as significant increase in plasma levels of corticosterone, adrenaline, noradrenaline, endothelin-1, nitric oxide and malondialdehyde with significant decrease in superoxide dismutase and these values are significantly more worse in chronic continuous exposure to noise than acute or chronic intermittent exposure. These findings suggest that noise stress has many adverse effects on cardiovascular system via increasing plasma levels of stress hormones, oxidative stress and endothelial dysfunction. These findings have major implication in the management of adverse cardiovascular reactions of people subjected to daily noise stress.
\end{abstract}

Key words: Noise - Cardiovascular system - Stress hormones - Oxidative stress - Endothelial dysfunction

Abbreviations: ECG, electrocardiogram; ET-1, endothelin-1; MDA, malondialdehyde; SOD, superoxide dismutase; ROS, reactive oxygen species.

\section{Introduction}

Noise has recently gained more attention as it becomes an integral part of our daily lives especially in industrial countries. Noise is defined as disturbing loud sound. Prevalence of noise is implicated in various illness of human and it is responsible for increased rates of morbidity and mortality (Franssen et al. 2004). This has encouraged scientists to study the effects of noise pollution on human's health (Mahmood et al. 2004). Beyond the direct damaging effect of noise, higher than $90 \mathrm{~dB}$ on the inner hair cells of the organ of Corti resulting in hearing loss, it also has several non-auditory effects including strokes (Münzel et al. 2014), sleep disturbance, decreased school performance, cognitive impairment, changes in the immune system (Babisch 2011),

Correspondence to: Mona Abdel-Azeem Said, Physiology Department, Faculty of Medicine, Benha University, Benha, Qalubia, Egypt E-mail: dr.monaabdelazim@gmail.com disturbed serum lipid, triglycerides, platelet count, plasma viscosity, glucose level and reduced motor efficiency (van Kempen et al. 2002). Noise is also associated with increased rates of work place accident as well as stimulating aggression and other anti-social behaviors (Maschke et al. 2002).

The cardiovascular effects of noise have been source of growing interest in recent years. This comes from the strong evidence that noise affects the cardiovascular system especially in industrialized countries and increases the risk of hypertension and ischemic heart diseases including atherosclerosis and myocardial infarction. Medium and high levels of urban traffic noise near kindergartens causes increased vascular tone and both systolic and diastolic blood pressure in preschool children (Regecová and Kellerová 1995). The general stress theory states that noise affects the autonomic nervous system and the endocrine system. However, to determine the magnitude of exposure-response and the possible modifying factors, more epidemiological and experimental studies are still needed (Babisch 2011). 
So we aimed in this study to investigate the effect of noise of intensity $(80-100 \mathrm{~dB})$ on heart rate and mean systemic arterial blood pressure in adult male albino rats and the possible role of stress hormones, markers of oxidative stress and endothelial dysfunction.

\section{Materials and Methods}

\section{Animals}

The present study was carried out on thirty two pathogenfree adult male albino Wistar rats 8-12 weeks old, weighing 200-250 g. The rats were housed in polypropylene cages under standard lightening (12 h light/dark cycle; 08:00 a.m.-08:00 p.m. light on) in a temperature-controlled room $\left(25 \pm 2{ }^{\circ} \mathrm{C}\right)$ and humidity $(50-70 \%)$. Rats were fed with a balanced diet and tap water. They were acclimatized to their environment for at least 2 weeks before starting the study. The animal procedures were performed in accordance with NIH guidelines and also were approved by the Local Institutional Animal Ethical Committee. Apart from the investigator, the animal care technician was the only person who entered the rooms. Background noise in experimental rooms did not exceed $35 \mathrm{~dB}$.

\section{Chemicals}

Xylazine (2\%) and ketamine (10\%) used in this study were purchased from Sigma-Aldrich Chemical Co. (St. Louis, MO, USA).

\section{Experimental design}

After the acclimatization period, the rats were randomly divided into four equal groups (8 rats per group) as follow according to Rahma et al. (2011).

Group I (Control group): This group was kept away from any noise stress source for 20 days.

Group II (Acute stress): Exposed to white noise (80-100 dB, $8000-16000 \mathrm{~Hz}$ ) for 12 hours once (from 8 a.m. to 8 p.m.)

Group III (Chronic intermittent stress): Exposed to white noise at the same intensity and frequency $(80-100 \mathrm{~dB}$, $8000-16000 \mathrm{~Hz}$ ) for 8 hours daily (from 8 a.m. to 4 p.m.) for 20 days ( 3 days exposure and 2 days without exposure).This intermittent exposure was to prevent the rats from becoming adapted to the noise.

Group IV (Chronic continuous stress): Exposed to white noise at same intensity and frequency $(80-100 \mathrm{~dB}$, $8000-16000 \mathrm{~Hz}$ ) for 8 hours daily (from 8 a.m. to 4 p.m.) for 20 consecutive days.

For this exposure, the groups were transported to a room of $3 \times 4 \times 3 \mathrm{~m}$ with wooden ground that has the same envi- ronmental and experimental conditions as the room where rats of the control group were kept, within which a noise generator (Tanta, Egypt) was placed.

\section{Calculation of heart rate}

After the last stress regimen of each group, the rats were anesthetized by xylazine $(10 \mathrm{mg} / \mathrm{kg})$ and ketamine $(100 \mathrm{mg} /$ $\mathrm{kg}$ ) and electrocardiograhic electrodes were connected to the four limbs by subcutaneous needles. The electrocardiograph was adjusted (each $20 \mathrm{~mm}$ height represent $1 \mathrm{mV}$ and the speed was $50 \mathrm{~mm} / \mathrm{s}$ ). Heart rate was detected from Lead II as it is the most informative of all leads (Chan et al. 1987).

\section{Measurement of arterial blood pressure}

For measuring systolic and diastolic arterial blood pressure, a longitudinal incision in the anterior aspect of the neck was done and the trachea was elevated to explore the carotid artery in which a carotid cannula connected to the oscillograph was inserted (The bioscience 400 series Washington oscillograph). Then mean systemic arterial blood pressure was calculated (Hicman 2001).

\section{Blood sample collection and biochemical assays}

After the blood pressure measuring, a cranio-caudal incision of about $2 \mathrm{~cm}$ was made, parallel and slightly to the left of the sternum through the skin and pectoral muscles to expose the ribs. A blunt curved forceps is then binged between the 5 th and 6 th ribs, through the intercostal muscles. The gap is widened so that the rapidly beating heart becomes visible. Intracardiac blood sample was drawn from the right ventricle and centrifuged at $5000 \times g$ for 15 minutes at room temperature $\left(25 \pm 2^{\circ} \mathrm{C}\right)$. The red blood cells (RBCs) will be separated at the bottom of the tube leaving clear plasma above. The clear supernatant (plasma) was kept at $-20^{\circ} \mathrm{C}$ for not more than 2 weeks to be used for biochemical assessment. Plasma corticosterone was measured by enzyme linked immunosorbent assay (ELISA) kits (DSL10-81100, Diagnostic systems laboratories Inc, USA) and plasma adrenaline and noradrenaline were measured using ELISA kits (EIA4776 and EIA4317, DRG International, Inc., USA) according to the method of Burtis and Ashweed (1994). The plasma level of nitric oxide (NO) was assessed indirectly by determining nitrite/nitrate level in the sample using standard commercial kits (ABIN955866, Antibodies Online, Germany) following Miranda et al. (2011) method. Plasma endothelin 1 (ET-1) was measured by radioimmunoassay using an antibody specific for ET-1 (RAS 6901, Peninsula Laboratories International, Inc., USA) following method of Brunner et al. (1994). Oxidative stress was as- 
sessed by measuring the plasma level of malondialdehyde (MDA) and superoxide dismutase (SOD) using commercial kits (ABIN627297 and ABIN2543481, Antibodies Online, Germany) following the method of Placer et al. (1966) and Kakkar et al. (1984).

\section{Statistical analysis}

All analyses were performed using the program "Statistical Package for Social Sciences (SPSS) version 16" (SPSS Inc, Chicago, IL, USA). The data are presented as the mean \pm standard deviation (SD). Comparisons among groups, in all studied parameters, were analyzed by using one-way analysis of variance (ANOVA) test and Post-Hoc multiple comparisons (Bonferroni's test). Probability of chance $(p<0.05)$ was considered statistically significant.

\section{Results}

Evaluation of heart rate (HR) and mean systemic arterial blood pressure (MSABP)

Table 1 shows that there is significant difference in heart rate and mean systemic arterial blood pressure among groups $(p<0.001)$. Mean systemic arterial blood pressure is significantly increased in acute stress, chronic intermittent stress and chronic continuous stress groups as compared with the control group. Heart rate and mean systemic arterial blood pressure are significantly higher in chronic continuous stress group as compared with both acute and chronic intermittent stress groups. However, there are non-significant changes between acute stress group and chronic intermittent stress group $(p>0.05)$.

\section{Evaluation of stress hormones}

Table 2 shows that there is significant difference in plasma levels of corticosterone, adrenaline and noradrenaline among groups $(p<0.001)$. Plasma levels of stress hormones are significantly increased in acute stress, chronic intermittent stress and chronic continuous stress groups as compared with the control group. This increase is significantly higher in chronic continuous stress as compared with both acute and chronic intermittent stress groups. However, there are non-significant changes between acute stress group and chronic intermittent stress group $(p>0.05)$.

\section{Evaluation of endothelial function}

Table 3 shows that there is significant difference in plasma levels of NO and ET-1among groups $(p<0.001)$. The plasma levels of NO and ET-1 are significantly increased in the acute stress, chronic intermittent stress and chronic continuous stress groups as compared with the control group. This increase is significantly higher in chronic continuous stress as compared with both acute and chronic intermittent stress groups. However, there are non-significant changes between acute stress group and chronic intermittent stress group $(p>0.05)$.

Table 1. Heart rate and mean systemic arterial blood pressure (MSABP) in the studied groups

\begin{tabular}{lccccc}
\hline Parameter & $\begin{array}{c}\text { Group I } \\
\text { (Control) }\end{array}$ & $\begin{array}{c}\text { Group II } \\
\text { (Acute Stress) }\end{array}$ & $\begin{array}{c}\text { Group III } \\
\text { (Chronic Intermittent Stress) }\end{array}$ & $\begin{array}{c}\text { Group IV } \\
\text { (Chronic Continuous Stress) }\end{array}$ & F test \\
\hline Heart rate (beats/min) & $274.17 \pm 17.44$ & $322.5 \pm 30.94$ & $325.83 \pm 25.77$ & $433.33 \pm 42.74^{* \dagger}$ & 28.88 \\
MSABP (mmHg) & $86.66 \pm 1.50$ & $93.5 \pm 2.43^{*}$ & $94.33 \pm 3.83^{*}$ & $118.83 \pm 5.45^{* \dagger}$ & 90.6 \\
\hline
\end{tabular}

Data is expressed as mean \pm standard deviation ( $n=8$ per group). $p<0.05$ is significant tested by using One-way analysis of variance (ANOVA) and Post Hoc multiple comparisons (Bonferroni's test). ${ }^{\star} p<0.001$ vs. control group; ${ }^{\dagger} p<0.001$ vs. acute stress group; ${ }^{\ddagger} p<0.001$ vs. chronic intermittent stress group.

Table 2. Plasma level of corticosterone, adrenaline and noradrenaline in the studied groups

\begin{tabular}{lccccc}
\hline & $\begin{array}{c}\text { Group I } \\
(\text { Control) }\end{array}$ & $\begin{array}{c}\text { Group II } \\
\text { Acute Stress) }\end{array}$ & $\begin{array}{c}\text { Group III } \\
\text { (Chronic Intermittent Stress) }\end{array}$ & $\begin{array}{c}\text { Group IV } \\
\text { (Chronic Continuous Stress) }\end{array}$ & F test \\
\hline Corticosterone $(\mathrm{ng} / \mathrm{ml})$ & $219.83 \pm 18.52$ & $400.33 \pm 23.64^{*}$ & $398.50 \pm 17.07^{*}$ & $586.83 \pm 27.21^{* \dagger \neq}$ & 278.7 \\
Adrenaline $(\mathrm{pg} / \mathrm{ml})$ & $402.60 \pm 69.69$ & $456.50 \pm 77.91^{*}$ & $457.83 \pm 82.08^{*}$ & $539.67 \pm 32.07^{* \dagger \neq}$ & 63.67 \\
Noradrenaline $(\mathrm{pg} / \mathrm{ml})$ & $208.33 \pm 69.76$ & $245.17 \pm 69.69^{*}$ & $247.67 \pm 76.07^{*}$ & $298.33 \pm 15.33^{* \dagger}$ & 85.08 \\
\hline Da
\end{tabular}

Data is expressed as mean \pm standard deviation ( $n=8$ per group). $p<0.05$ is significant tested by using One-way analysis of variance (ANOVA) and Post Hoc multiple comparisons (Bonferroni's test). ${ }^{\star} p<0.001$ vs. control group; ${ }^{\dagger} p<0.001$ vs. acute stress group; ${ }^{\ddagger} p<0.001$ vs. chronic intermittent stress group. 


\section{Assessment of oxidative stress}

Table 4 shows that there is significant difference in plasma levels of MDA and SOD among groups $(p<0.001)$. The plasma levels of MDA is significantly increased while SOD is significantly decreased in acute stress, chronic intermittent stress and chronic continuous stress groups as compared with the control group. These changes are significantly higher in chronic continuous stress as compared with both acute and chronic intermittent stress groups. However, there are non-significant changes between acute stress group and chronic intermittent stress group $(p>0.05)$.

\section{Discussion}

World Health Organization (WHO) declared noise as an international health problem being one of the most wide spread sources of environmental stress in human life. Noise stress has many negative effects on various organs of our body especially the cardiovascular system (Passchier-Vermeer and Passchier 2000; Wallenius 2004). The results of the present study revealed that heart rate is significantly elevated in rats exposed to chronic continuous noise stress as compared to the control, acute stress and chronic intermittent stress groups. Mean systemic arterial blood pressure is significantly elevated in rats exposed to acute or chronic noise stress as compared to the control group and this elevation is significantly higher in chronic continuous noise-stressed rats as compared with acute or chronic intermittent stress groups. These findings are consistent with previously published studies (van Kempen et al. 2002; Bluhm and Eriksson 2011; Lercher et al. 2011). The adverse effects of acute or chronic noise stress on cardiovascular system may be explained by increased reactive oxygen species, increased release of stress hormones, activation of sympathetic nervous system, increasing blood viscosity, endothelial dysfunction, peripheral vasoconstriction, and increase peripheral vascular resistance (Baldwin 2007; Baldwin et al. 2008; Babisch 2011; Münzel et al. 2014).

Stress hormones; cortisol, adrenaline and noradrenaline are used as indicators of body response to stress upon noise exposure (Spreng 2000; Li et al. 2009). Pituitary-adrenocortical axis is involved in the extra-auditory effects of noise (Ising and Braun 2002; Kanitz et al. 2005). The results of the current work show that rats exposed to acute or chronic noise have significantly elevated plasma levels of corticosterone, adrenaline and noradrenaline as compared to the control rats unexposed to noise and this elevation is significantly higher in chronic continuous stress group as compared with both acute or chronic intermittent stress groups. These findings are congruent to the previous studies which concluded that rats exposed to noise showed elevated plasma levels of corticosterone (Soldani et al. 1999; Samson et al. 2007; Gannouni et al. 2013), adrenaline and noradrenaline (Maschke et al. 2002; Lenzi et al. 2003; Maschke 2003; Di et al. 2011; Schmidt et al. 2013). These endocrinal changes in response to exposure to noise stress can be explained by activation of autonomic nervous system (Turner et al. 2005) or structural and functional modifications occurring in the adrenal cortex and medulla which are supposed to be mediated by increased free oxygen radicals (Soldani et al. 1999; Kanitz et

Table 3. Plasma level of nitric oxide (NO) and endothelin 1 (ET-1) in the studied groups

\begin{tabular}{lccccc}
\hline & $\begin{array}{c}\text { Group I } \\
(\text { Control })\end{array}$ & $\begin{array}{c}\text { Group II } \\
(\text { Acute Stress })\end{array}$ & $\begin{array}{c}\text { Group III } \\
(\text { Chronic Intermittent Stress })\end{array}$ & $\begin{array}{c}\text { Group IV } \\
(\text { Chronic Continuous Stress })\end{array}$ & F test \\
\hline $\mathrm{NO}(\mu \mathrm{mol} / \mathrm{ml})$ & $50.91 \pm 3.81$ & $71.21 \pm 3.12^{*}$ & $72.08 \pm 4.17^{*}$ & $91.72 \pm 4.13^{* \dagger}$ & 113.37 \\
$\mathrm{ET}-1(\mathrm{pg} / \mathrm{ml})$ & $41.08 \pm 2.41$ & $51.75 \pm 2.44^{*}$ & $52.50 \pm 2.54^{*}$ & $70.08 \pm 3.41^{* \dagger}$ & 115.56 \\
\hline
\end{tabular}

Data is expressed as mean \pm standard deviation ( $n=8$ per group). $p<0.05$ is significant tested by using One-way analysis of variance (ANOVA) and Post Hoc multiple comparisons (Bonferroni's test). ${ }^{\star} p<0.001 v s$. control group; ${ }^{\dagger} p<0.001$ vs. acute stress group; ${ }^{\ddagger} p<0.001 v$ s. chronic intermittent stress group.

Table 4. Plasma level of malondialdehyde (MDA) and superoxide dismutase (SOD) in the studied groups

\begin{tabular}{lccccc}
\hline & $\begin{array}{c}\text { Group I } \\
\text { (Control) }\end{array}$ & $\begin{array}{c}\text { Group II } \\
\text { (Acute Stress) }\end{array}$ & $\begin{array}{c}\text { Group III } \\
\text { (Chronic Intermittent Stress) }\end{array}$ & $\begin{array}{c}\text { Group IV } \\
\text { (Chronic Continuous Stress) }\end{array}$ & F test \\
\hline $\mathrm{MDA}(\mathrm{nmol} / \mathrm{ml})$ & $3.05 \pm 0.42$ & $4.10 \pm 0.32^{*}$ & $4.16 \pm 0.39^{*}$ & $5.65 \pm 0.33^{* \dagger}$ & 49.68 \\
SOD $(\mathrm{U} / \mathrm{ml})$ & $30.66 \pm 1.08$ & $28.25 \pm 0.93^{*}$ & $27.96 \pm 1.05^{*}$ & $24.5 \pm 0.89^{* \dagger \ddagger}$ & 39.17 \\
\hline
\end{tabular}

Data is expressed as mean \pm standard deviation ( $n=8$ per group). $p<0.05$ is significant tested by using One-way analysis of variance (ANOVA) and Post Hoc multiple comparisons (Bonferroni's test). ${ }^{\star} p<0.001 v$ s. control group; ${ }^{\dagger} p<0.001 v s$. acute stress group; ${ }^{\ddagger} p<0.001$ vs. chronic intermittent stress group. 
al. 2005; Gannouni et al. 2013). Also it was postulated that elevated corticosterone accelerates the generation of free oxygen radicals (McIntosh and Sapolsky 1996). Increased level of stress hormones, activation of sympathetic nervous system, increasing the density of noradrenergic fibers in the heart and catecholamine-induced increase in $\mathrm{Ca}^{2+}$ entry to the myocardium can explain the increase in heart rate and systolic blood pressure upon exposure to loud noise (Lenzi et al. 2003).

Reactive oxygen species (ROS) or free oxygen radicals are normally produced as sequence of aerobic metabolism. They cause breakdown of lipid molecules of cell membrane which is known as lipid peroxidation as well as impairment of proteins and deoxyribonucleic acid (DNA) (Van Campen et al. 2002). Under normal conditions, the endogenous antioxidants protect the cell from the damaging effect of free oxygen radicals (Henderson et al. 2006). Oxidative stress is a state of imbalance between oxidants and antioxidants leading to cellular damage, dysfunction or death (Demirel et al. 2009). Oxidative stress is found to be a common denominator in many aspects of heart-related diseases (Blum 2009). One of the consequences of noise exposure is increased production of ROS, as superoxide, hydrogen peroxide and hydroxyl radicals (Gannouni et al. 2013). In this study, the lipid peroxidation level, indicated by increased the plasma level of MDA (Nielsen et al. 1997), is significantly increased in rats exposed to acute, chronic intermittent or continuous noise stress compared to the normal control rats and this increase is significantly higher in chronic continuous stress than acute or chronic intermittent stress. Also in the current study, it is found out that exposure to acute or chronic noise decreases the antioxidant enzyme, SOD. These findings agreed the previous studies done in rats (Demirel et al. 2009), rabbits (Derekoy et al. 2001) and human (Yildirim et al. 2007). Free oxygen radicals generated as a result of exposure to acute or chronic loud noise are involved in nervous, endocrine and cardiovascular disorders (Manikandan et al. 2005).In cardiovascular system, they cause hypertrophy of smooth muscle cells and arterial wall, cardiomyocyte necrosis and apoptosis and myocardial damage that can be attributed to increased heart rate and systolic blood pressure in noise-stressed rats (Gesi et al. 2002; Abu-Amara et al. 2013).The findings of the present study regarding SOD are in contrast to other findings which postulated that the plasma levels of antioxidant enzymes as SOD and catalase are elevated in rats exposed to long-term noise of moderate intensity $(70$ and $85 \mathrm{~dB})$ and this might be a protective mechanism (Gannouni et al. 2013). This difference may be due to the difference in the duration and/or the amplitude of the noise applied in the study.

Noise impairs endothelial function which may be partly mediated by ROS (Schmidt et al. 2013, 2015). In the current work, acute, chronic intermittent and chronic continuous stress, cause significant increase in the plasma levels of NO and ET- 1 as compared with the control group. This increase is significantly higher in chronic continuous noise stressed rats when compared with acute or chronic intermittent stress groups. Elevated plasma level of ET-1 in response to noise stress causes peripheral vasoconstriction and increases arterial blood pressure (Wang et al. 2002). The increase in NO level may be due to elevated NO synthase activity and elevated nitrate/nitrite levels in the heart and aorta (Bernatova et al. 2007). Increased generation of reactive oxygen species induced by elevated corticosterone level in response to noise stress (McIntosh and Sapolsky 1996) can also explain increased NO level via enhancing inactivation of nitric oxide (Vaziri et al. 1999) or inducing the signal transduction pathways for nitric oxide synthase (iNOS) (Yoshikawa et al. 2000). NO is accepted as oxygen free radical that has harmful effects on cardiovascular system (Demirel et al. 2009). This finding is in agreement with the study of Puzserova et al. who postulated that long-term exposure to chronic social stress reduced the NO-independent relaxation in normotensive rats that might be the initial step in chronic stress-induced cardiovascular disorders (Puzserova et al. 2013). In contrast to our finding, other researchers postulated that the level of NO in erythrocytes of workers in noisy workplaces is lower than the workers in non-noisy places and this could be an adaptive mechanism to chronic exposure to loud noise (Pinar et al. 2011).

From the results of the current work, we conclude that exposure to noise has deleterious effects on the cardiovascular system as indicated by increased heart rate and mean systemic arterial blood pressure and therefore we suggest the precise monitoring of noise exposure. Because oxidative stress, endothelial dysfunction and elevated stress hormones are implicated in the negative effects of noise on cardiovascular system, they should be considered in the strategy for controlling the adverse effect of noise on the human health.

Conflict of interest. The authors declare that they have no conflict of interest.

\section{References}

Abu-Amara T. M., Elgharabawi G. S., Motawee M. E., Mourad S. E., Taha N. M. (2013): Effect of noise stress on lung and heart of adult albino rats and the possible protective role of sulpiride. The Egyptian journal of hospital medicine 53, 1083-1105 http://dx.doi.org/10.12816/0001670

Babisch W. (2011): Cardiovascular effects of noise. Noise Health 13, 201-204 http://dx.doi.org/10.4103/1463-1741.80148

Baldwin A. L. (2007): Effects of noise on rodent physiology. Int. J. Comp. Psychol. 20, 134-144 
Baldwin A. L., Wagers C., Schwartz G. E. (2008): Reiki improves heart rate homeostasis in laboratory rats. J. Altern. Complement. Med. 14, 417-422 http://dx.doi.org/10.1089/acm.2007.0753

Bernatova I., Puzserova A., Navarova J., Csizmadiova Z., Zeman M. (2007): Crowding-induced alterations in vascular system of Wistar-Kyoto rats: role of nitric oxide. Physiol. Res. 56, 667-669

Bluhm G., Eriksson C. (2011): Cardiovascular effects of environmental noise: Research in Sweden. Noise Health 13, $212-216$ http://dx.doi.org/10.4103/1463-1741.80152

Blum A. (2009): Heart failure - New insights. Isr. Med. Assoc. J. 11, 105-111

Brunner F., Stessel H., Simecek S., Graier W., Kukovetz W.R. (1994): Effect of intracellular Ca2+ concentration on endothelin-1 secretion. FEBS Lett. 350, 33-36 http://dx.doi.org/10.1016/0014-5793(94)00727-6

Burtis C. A., Ashweed E. R. (1994): Tietz Textbook of Clinical Chemistry (2nd ed.), pp. 1825-1827, W.B. Saunders Company, Philadelphia

Chan M. Y, Dai S., Ko W. W. (1987): Effect of morphine on cardiovascular response to acute myocardial infarction in rats. Br. J. Pharm. 90, 537-543 http://dx.doi.org/10.1111/j.1476-5381.1987.tb11203.x

Demirel R., Mollaoğlu H., Yeşilyurt H., Üçok K., Ayçiçek A., Akkaya M., Genç A., Uygur R., Doğan M. (2009): Noise induces oxidative stress in rat. Eur. J. Gen. Med. 6, 20-24

Derekoy F. S., Dundar Y., Aslan R., Cangal A. (2001): Influence of noise exposure on antioxidant system and TEOAEs in rabbits. Eur. Arch. Otorhinolaryngol. 258, 518-522 http://dx.doi.org/10.1007/s004050100388

Di G. Q., Zhou B., Li Z. G., Lin Q. L. (2011): Aircraft noise exposure affects rat behavior, plasma norepinephrine levels, and cell morphology of the temporal lobe. J. Zhejiang Univ. Sci. B. 12, 969-975 http://dx.doi.org/10.1631/jzus.B1000439

Franssen E. A. M., van Wiechen C. M. A. G., Nagelkerke N. J. D., Lebret E. (2004): Aircraft noise around a large international airport and its impact on general health and medication use. Occup. Environ. Med. 61, 405-413 http://dx.doi.org/10.1136/oem.2002.005488

Gannouni N., Mhamdi A., Tebourbi O., El May M., Sakly M., Rhouma K. B.(2013): Qualitative and quantitative assessment of noise at moderate intensities on extra-auditory system in adult rats. Noise Health 15, 406-411 http://dx.doi.org/10.4103/1463-1741.121236

Gesi M., Lenzi P., Fornai F., Ferrucci M., Soldani P., Pellegrini A., Paparelli A. (2002): Effects of loud noise exposure on mouse myocardium: a comparison with the rat. Microsc. Res. Tech. 59, 131-135 http://dx.doi.org/10.1002/jemt.10185

Henderson D., Bielefeld E. C., Harris K. C., Hu B. H. (2006): The role of oxidative stress in noise-induced hearing loss. Ear Hear 27, 1-19 http://dx.doi.org/10.1097/01.aud.0000191942.36672.f3

Hicman I. (2001): Oscilloscopes: How to Use Them, How They Work. (5th ed.), pp. 88-91, Oxford, Boston
Ising H., Braun C. (2002): Acute and chronic endocrine effects of noise: Review of the research conducted at the Institute for Water, Soil and Air Hygiene. Noise Health 2, 7-24

Kakkar P., Das B., Viswanathan P. N. (1984): A modified spectrophotometric assay of superoxide dismutase. Indian J. Biochem. Biophys. 21, 130-132

Kanitz E., Otten W. Tuchscherer M. (2005): Central and peripheral effects of repeated noise stress on hypothalamic-pituitary-adrenocortical axis in pigs. Livestock Production Science 94, 213-224 http://dx.doi.org/10.1016/j.livprodsci.2004.12.002

Lenzi P., Frenzilli G., Gesi M., Ferrucci M., Lazzeri G., Fornai F., Nigro M. (2003): DNA damage associated with ultrastructural alterations in rat myocardium after loud noise exposure. Environ. Health Perspect. 111, 467-471 http://dx.doi.org/10.1289/ehp.5847

Lercher P., Botteldooren D., Widmann U., Uhrner U., Kammeringer E. (2011): Cardiovascular effects of environmental noise: Research in Austria. Noise Health 13, 234-250 http://dx.doi.org/10.4103/1463-1741.80160

Li H., Ma X. Q., Ye F., Zhang J., Zhou X., Wang Z. H., Li Y. M., Zhang G. Y. (2009): Expressions of cardiac sympathetic norepinephrine transporter and $\beta 1$-adrenergic receptor decreased in aged rats. J. Zhejiang Univ. Sci. B. 10, 203-210 http://dx.doi.org/10.1631/jzus.B0820213

Mahmood R., Khan G. J., Alam S., Safi A. J., Salahuddin, Amin-ulHaq. (2004): Effect of 90 decibel noise of 4000 Hertz on blood pressure in young adults. J. Ayub Med. Coll. Abbottabad. 16, $30-33$

Manikandan S., Srikumar R., Parthasarathy N. J., Devi R. S. (2005): Protective effect of acorus calamus LINN on free radical scavengers and lipid peroxidation in discrete regions of brain against noise stress exposed rat. Biol. Pharm. Bull. 28, 2327-2330 http://dx.doi.org/10.1248/bpb.28.2327

Maschke C., Harder J., Ising H., Hecht K. (2002): Stress hormone changes in persons under simulated night noise exposure. Noise Health 5, 35-45 Maschke C. (2003): Stress hormone changes in persons exposed to stimulated night noise. Noise Health 5, 35-45

McIntosh L. J., Sapolsky R. M. (1996): Glucocorticoids increase the accumulation of reactive oxygen species and enhance adriamycin-induced toxicity in neuronal culture. Exp. Neurol. 141, 201-206 http://dx.doi.org/10.1006/exnr.1996.0154

Miranda K. M., Espey M. G., Wink D. A. (2001): A rapid, simple spectrophotometric method for simultaneous detection of nitrate and nitrite. Nitric Oxide 5, 62-71 http://dx.doi.org/10.1006/niox.2000.0319

Münzel T., Gori T., Babisch W., Basner M. (2014): Cardiovascular effects of environmental noise exposure. Eur. Heart J. 35, $829-836$ http://dx.doi.org/10.1093/eurheartj/ehu030

Nielsen F., Mikkelsen B. B., Nielsen J. B., Andersen H. R., Grandjean P. (1997): Plasma malondialdehyde as biomarker for oxidative stress: reference interval and effects of life-style factors. Clin. Chem. 43, 1209-1214

Passchier-Vermeer W., Passchier W. F. (2000): Noise exposure and public health. Environ. Health Perspect. 108, 123-131 http://dx.doi.org/10.1289/ehp.00108s1123 
Placer Z. A., Cushman L. L., Johnson B. C. (1966): Estimation of product of lipid peroxidation (malonyldialdehyde) in biochemical systems. Anal Biochem. 16, 359-364 http://dx.doi.org/10.1016/0003-2697(66)90167-9

Pinar T., Atli A. K., Alacam H., Karabulut I., Soguksulu I., Atas A., Omar M. B., Amin N. A., Akyol O. (2011): The effects of noise on oxidative and antioxidative balance in human Erythrocytes. International Journal of Hematology and Oncology 1, 10-18 http://dx.doi.org/10.4999/uhod.10094

Puzserova A., Slezak P., Balis P., Bernatova I. (2013): Long-term social stress induces nitric oxide-independent endothelial dysfunction in normotensive rats. Stress 16, 331-339 http://dx.doi.org/10.3109/10253890.2012.725116

Rahma M. S., Win N. N., Rafidah H. M., Ailin R. (2011): The effects of noise on biochemical parameters using rat's hearts. European Journal of Scientific Research 56, 93-96

Regecová V., Kellerová E. (1995): Effects of urban noise pollution on blood pressure and heart rate in preschool children. J. Hypertens. 13, 405-412 http://dx.doi.org/10.1097/00004872-199504000-00005

Samson J., Sheeladevi R., Ravindran R., Senthilvelan M. (2007): Stress response in rat brain after different durations of noise exposure. Neurosci. Res. 57, 143-147 http://dx.doi.org/10.1016/j.neures.2006.09.019

Schmidt F. P., Basner M., Kröger G., Weck S., Schnorbus B., Muttray A., Sariyar M., Binder H., Gori T., Warnholtz A., Münzel T. (2013): Effect of nighttime aircraft noise exposure on endothelial function and stress hormone release in healthy adults. Eur. Heart J. 34, 3508-3514 http://dx.doi.org/10.1093/eurheartj/eht269

Schmidt F., Kolle K., Kreuder K., Schnorbus B., Wild P., Hechtner M., Binder H., Gori T., Münzel T. (2015): Nighttime aircraft noise impairs endothelial function and increases blood pressure in patients with or at high risk for coronary artery disease. Clin. Res. Cardiol. 104, 23-30 http://dx.doi.org/10.1007/s00392-014-0751-x

Soldani P., Gesi M., Lenzi P., Natale G., Fornai F., Pellegrini A., Ricciardi M.P., Paparelli A. (1999): Long-term exposure to noise modifies rat adrenal cortex ultrastructure and corticosterone plasma levels. J. Submicrosc. Cytol. Pathol. 31, 441-448

Spreng M. (2000): Possible health effects of noise induced cortisol increase. Noise Health 2, 59-63

Turner J. G., Parrish J. L., Hughes L. F., Toth L. A., Caspary D. M. (2005): Hearing in laboratory animals: strain differences and non-auditory effects of noise. Comp. Med. 55, 12-23

van Kempen E. E., Kruize H., Boshuizen H. C., Ameling C. B., Staatsen B. A., de Hollander A. E. (2002): The association between noise exposure and blood pressure and ischemic heart disease: a meta-analysis. Environ. Health Perspect. 110, 307-317 http://dx.doi.org/10.1289/ehp.02110307

Van Campen L. E., Murphy W. J., Franks J. R., Mathias P. I., Toraason M. A. (2002): Oxidative DNA damage is associated with intense noise exposure in the rat. Hear Res. 164, 29-38 http://dx.doi.org/10.1016/S0378-5955(01)00391-4

Vaziri N. D., Liang k., Ding Y. (1999): Increased nitric oxide inactivation by reactive oxygen species in lead-induced hypertension. Kidney Int. 56, 1492-1498 http://dx.doi.org/10.1046/j.1523-1755.1999.00670.x

Wallenius M. A. (2004): The interaction of noise stress and personal project stress on subjective health. Journal of Environmental Psychology 24, 167-177 http://dx.doi.org/10.1016/j.jenvp.2003.12.002

Wang C., Wang R., Zhao S. et al. (2002): The effects of combined exposure of heat and noise on workers' blood pressure plasma endothelin and ANP. Chinese Occup. Med. 2002-05

Yildirim I., Kilinc M., Okur E., InancTolun F., Kiliç M. A., Kurutas E. B., Ekerbiçer H. C. (2007): The effects of noise on hearing and oxidative stress in textile workers. Ind. Health 45, 743-749 http://dx.doi.org/10.2486/indhealth.45.743

Yoshikawa T., Tanigawa M., Tanigawa T., Imai A., Hongo H., Kondo M. (2000): Enhancement of nitric oxide generation by low frequency electromagnetic field. Pathophysiology 7, 131-135 http://dx.doi.org/10.1016/S0928-4680(00)00040-7

Received: July 8, 2015

Final version accepted: January 20, 2016

First published online: May 13, 2016 